\title{
Matematik Öğretim Programı Dersinde Edmodo Sosyal Paylaşım Platformunun Kullanımı: Öğretmen Adaylarının Görüşleri*
}

\author{
Nilgün Günbaş ${ }^{* *}$, Hilal Yıldız***
}

Makale Geliş Tarihi: 27/09/2018

Makale Kabul Tarihi: 03/12/2018

DOI: $10.35675 /$ befdergi. 478788

$\ddot{O} z$

Bu çalışmanın amacı eğitsel bir sosyal paylaşım platformu olan Edmodo'nun Matematik Öğretim Programı dersi kapsamında kullanımı ile ilgili öğretmen adaylarının görüşlerini ortaya çıkarmaktır. Bu amaç doğrultusunda bir devlet üniversitesinde 2017-2018 EğitimÖğretim yll bahar döneminde 42 ögretmen adayı $(K=22, E=20)$ ders kapsamında Edmodo platformunu dönem boyunca kullanmış ve dönem sonunda bu platform ile ilgili görüşleri sorulmuştur. Çalışmada nitel araştırma yöntemlerinden durum çalışmass deseni kullanılmıştır. Betimsel analiz ile belirlenen bulgulara göre öğretmen adaylarına göre bu ortam erişim kolaylığı sağlayan, derse katılımı ve ilgiyi arttıran, iletişim kolaylı̆̆ ve zaman tasarrufu sağlayan, dersi eğlenceli hale getiren, geri dönüt alarak bilgilerini kontrol edebilme imkânı sağlayan ve eğitimde teknoloji deneyimi yaşatan olumlu bir atmosfere sahiptir. Dolaylsiyla ögretmen adayları Edmodo'nun kullanımının diğer dersler için de yaygınlaştırılması gerektiğ $i$ görüşündedir. Özellikle Edmodo'nun mobil uygulamasını kullanmayı tercih eden öğretmen adayları, uygulama dilinin Ingilizce olması ve bildirim gelmemesi nedeniyle ödevleri geç fark etmelerini sorun olarak bildirmişlerdir.

Anahtar Kelimeler: Edmodo, matematik öğretim programı, matematik öğretmen adayl, sosyal paylaşım platformu.

\section{Use of Edmodo Social Networking Website in Mathematics Curriculum Class: Pre-service Teachers' Views}

\section{Abstract}

The purpose of this study is to reveal pre-service mathematics teachers' views about the use of Edmodo social networking site in Mathematics Curriculum class. For this purpose, Edmodo platform was used in the spring semester of 2017-2018 academic year. 42 pre-service mathematics teachers $(F=22, M=20)$ used the platform and were asked for their views about this experience. A case study was used in this study. Based on the descriptive analysis results, pre-service teachers think that Edmodo provides accessibility and ease of communication,

\footnotetext{
* Bu çalışmanın kısa bir özeti 6. Uluslararası Eğitim Programları ve Öğretim Kongresi’nde sözlü bildiri olarak sunulmuştur.

** Kafkas Üniversitesi, Eğitim Fakültesi, Matematik ve Fen Bilimleri Eğitimi Bölümü, Kars, Türkiye, ngunbas@gmail.com ORCID: 0000-0003-2578-3083

**** Kafkas Üniversitesi, Eğitim Fakültesi, Matematik ve Fen Bilimleri Eğitimi Bölümü, Kars, Türkiye, hilalaslanbas@hotmail.com ORCID: 0000-0001-9841-9130 (DD
}

Kaynak Gösterme: Günbaş, N. \& Yıldız, H. (2020). Matematik öğretim programı dersinde Edmodo sosyal paylaşım platformunun kullanımı: Öğretmen adaylarının görüşleri. Bayburt Eğitim Fakültesi Dergisi, 15(29), 109-129. https://doi.org/10.35675/befdergi.478788 
increases interest and class participation. It helps creating a positive class atmosphere, makes class fun, provides technology experience in education and helpful with feedback. They recommend Edmodo should be used in other classes as well. Especially, pre-service teachers, who preferred using Edmodo on mobile devices, reported some problems with the platform: the language of the site was English and homework notifications did not come regularly.

Keywords: Edmodo, mathematics curriculum, mathematics pre-service teachers, social networking

\section{Giriş}

Web 2.0 uygulamaları kullanıcılar tarafindan sürekli güncellenen, kendi verilerini giren ve katılımlarıyla ağ etkisi oluşturan bu kullanıcılardan veri alan ve bu verileri kullanan uygulamalardır (O’Reilly, 2007). Facebook, Blogger, Twitter gibi örnekleri bulunan bu uygulamalar insanların bağlantılı oldukları arkadaşlarından ve diğer kişilerden multimedya güncellemeleri almalarını, bu kişilerle bağlantı kurmalarını ve kendilerine ait bir profil oluşturmalarını sağlayan ortamlardır (Newman, Chang, Walters \& Wills, 2016). Bu uygulamalar aynı zamanda öğrencilerin sosyal ortamlarda bağlantı kurmalarını ve öğrenmelerini de desteklemektedir. Yüksek öğrenim kurumlarında özellikle işbirlikli öğrenmeyi ve öğrenci performansını desteklediği düşünülen bu ortamlara doğru son zamanlarda bir yönelme olduğu görülmektedir (AlRahmi \& Zeki, 2017). Edmunds, Thorpe ve Conole (2012)'e göre bu ortamlar öğrencilerin iş ortamlarında belirli teknolojileri kullanmasını, bu ortamlardaki etkililiklerini arttıran becerilerini ve bu becerileri geliştirme farkındalıklarını da yakından etkilemektedir.

Güncel eğitim ortamları özellikle işbirliği ve sosyal etkileşime önem vermekte ve dolayısıyla bu iki kavramı ön plana alarak öğrencilerin öğrenmelerini destekleyecek şekilde eğitim ortamları tasarlanmaya çalışılmaktadır (Al-Abri, Jamoussi, Kraiem \& Al-Khanjari, 2017). Web 2.0 araçları olan sosyal paylaşım platformları iletişim ve işbirliği içerisinde öğrencilerin öğrenmelerini destekleyecek şekilde kullanılabilir. Bu platformlar geleneksel yüz yüze verilen eğitimin yerini almak yerine bu eğitimin bir tamamlayıcısı olarak eğitimsel süreçleri geliştirmek amacıyla kullanılabilirler (Porcel, Ching-López, Lefranc, Loia \& Herrera-Viedma, 2018). Bu platformlarda öğrenciler öğretmenleri ve arkadaşları ile sosyal etkileşimde bulunabilir, paylaşımları takip ederek öğrenebilir, diğerleri tarafından yapılmış ödevlerden yararlanabilir, ortaklaşa ya da bireysel ödevler hazırlayabilir, sosyal gruplara katılabilir, zaman ve mekândan bağımsız olarak materyallere erişebilirler (Alkan \& Bardakçı, 2017).

Bir sosyal paylaşım platformu olan Edmodo, öğrenciler, öğretmenler ve veliler için tasarlanan ve onların işbirlikçi bir ortamda iletişime geçebildikleri, ödevlere erişebildikleri, paylaşımlarda bulunabildikleri ve başarı notlarını görebildikleri bir ortamdır (Balasubramanian, Jaykumar \& Fukey, 2014; McLean, Edwards \& Morris, 2017). Özellikle eğitimde kullanılmak üzere tasarlanan ve eğitimin Facebook’u olarak adlandırılan Edmodo (Sarrab, Elbasir \& Alnaeli, 2016), öğrenciler için teknolojik, 
sosyal, eğitimsel ve ücretsiz bir iletişim ortamıdır (Porcel, Ching López, Lefranc, Loia \& Herrera Viedma, 2018). Öğrenciler quiz ve ödev gibi ölçme araçlarına uzaktan erişim ile ulaşabilirken, öğretmenler ölçme ve değerlendirmeleri yine Edmodo üzerinden yapabilmektedirler. Özellikle quiz ve ödevler için öğretmenler sınıfın genel durumunu görebilir, öğrenciler aldıkları dönütlerle kendilerini değerlendirebilir ve veliler çocuklarının ders durumunu takip edebilir.

Edmodo, geleneksel öğretimin ötesine geçerek zaman ve mekân kısıtlılığı olmaksızın öğretmenler ve öğrencilerin bağlantı kurabildikleri, etkileşime geçebildikleri, işbirliği yapabildikleri, içerik paylaşabildikleri ve öğretmenlerin çevrimiçi bir ortamda öğrencilerin çalışmalarını görebildikleri güvenli bir ortam olarak düşünülmektedir (Sarrab, Elbasir \& Alnaeli, 2016). Facebook gibi sosyal medya ortamları eğitim araştırmalarına konu olmuştur. Fakat bu ortamlar öğrencilerin dikkatini dağıtabilmektedir. Edmodo öğrencilere işbirlikli bir eğitim ortamında sadece eğitim amaçlı kullanılabilecek bir ortam olarak tasarlanmıştır.

Edmodo son yıllarda eğitim araştırmalarında sıklıkla kullanılmaktadır. Örneğin, Aldemir, Çelik ve Kaplan (2018) yaptıkları çalışmada, tasarladıkları oyun öğelerini (avatar, rozet gibi) Edmodo içerisine entegre ederek öğrencilerin bu öğeler ile ilgili genel algısını ortaya çıkarmak için kullanmışlardır. Aynı zamanda Edmodo ortamında bir çevrimiçi topluluk oluşturarak, sistem üzerinden öğrencilerin iletişim kurmalarını amaçlamışlardır. McLean, Edwards ve Morris (2017) çalışmalarında, velilerin Edmodo platformunu kullanarak çocuklarının altı haftalık bir zaman dilimi içerisinde oynadıkları oyunlar (örneğin fiziksel, motor beceri geliştirici ve keşfedici türde) ile ilgili bakış açılarını paylaşmaları için kullanmışlardır.

Alanyazın incelendiğinde, Edmodo'nun farklı seviyede bireylerle eğitim amaçlı kullanıldığı görülmektedir. Örneğin, Trust (2017) çalışmasında, öğretmenlerin matematik dersinde Edmodo kullanımının kendi öğrenmeleri ve uygulamalarını nasıl şekillendirdiğini incelemiştir. 150 katılımcı ile çevrimiçi bir anketle gerçekleştirdikleri çalışmanın sonucu olarak öğretmenler, öğretim uygulamalarını geliştirmek için motivasyon kazandıklarını, uygulamalarında değişiklik yapmak için kendilerini daha güçlü hissettiklerini ve öğrenci merkezli ve yenilikçi uygulamaları daha iyi hayata geçirebileceklerini bildirmişlerdir. Dere, Yücel ve Yalçınalp (2016) ilköğretim öğrencilerinin Edmodo'nun özellikleriyle ve derste kullanılmasılla ile ilgili görüşlerini ortaya çıkarmaya çalıştıkları karma desenli bir durum çalışmasında, öğrencilerin Edmodo’yu öğrenmelerini destekleyici bir ortam olarak gördüklerini ortaya çıkarmışlardır. Hamutoğlu ve Kıyıcı (2017) bir eğitim fakültesinin 1. sınıf öğrencileri ile yaptıkları çalışmalarında, yeni okuryazarlıklar dersinde Edmodo kullanmışlar ve 37 öğrencinin görüşünü almışlardır. Öğrenciler Edmodo'nun derse odaklanmalarını arttırdığını, öğrenmelerine katkı sağladığını, zaman ve mekân sınırlılığı olmaksızın ders dokümanlarına kolaylıkla erişebildiklerini belirtmişlerdir. Kazez ve Bahçeci (2016) Bilgisayar ve Öğretim Teknolojileri (BÖTE) bölümü 2. sınıf öğrencileriyle yürüttükleri Grafik ve Tasarım dersinde Edmodo platformunu 
kullanmışlardır. Öğrencilerden aldıkları görüşler neticesinde, onlara sunulan sürekli dönütlerin derslere olan ilgilerini arttığını ve ödev hazırlamalarında onları motive ettiği bulgusuna ulaşmışlardır. Baştuğ, Solmaz, Kaledibi ve İşbulan (2016) 111 ilköğretim 5. ve 6. sınıf öğrencisine kodlama eğitimi vermiş, bu kapsamda Edmodo platformunu kullanmış ve bu platforma karşı öğrencilerin algısını ölçmüşlerdir. Sonuç olarak, Edmodo'ya karşı öğrencilerin algılarının yüksek ve olumlu olduğunu, çekingen öğrencilere iletişim konusunda destek olduğunu, aktif öğrenmeyi desteklediğini, fakat internet erişimi probleminin öğrencilerin algılarını olumsuz yönde etkilediği bulgusuna rastlamışlardır.

Edmodo'nun aynı zamanda ders dokümanlarının dijital ortamda depolandığ1 klinik öğrenme ortamlarında (Taşgın \& Küçükoğlu, 2016) ve harmanlanmış öğrenme ortamlarında kullanıldığı da görülmektedir. Örneğin Kurt (2017), ilköğretim matematik öğretmenliği 3. sınıf öğrencileri ile gerçekleştirdiği çalışmasında, Ölçme ve Değerlendirme dersinde Kuantum öğrenme basamaklarından yararlanmıştır. Bunun için harmanlanmış öğretimin çevrimiçi kısmında yakalama, ilişkilendirme, tekrarlama ve kutlama basamaklarını, yüz yüze kısmında ise etiketleme ve gösterme basamaklarını kullanmışı̧ır. Çevrimiçi kısmında Edmodo'dan yararlanmış ve bu ortamda günlük tutma, zihin haritaları, mektup yazma gibi etkinlikler yapmış ve öğrencileri ayrıca haftalık quizlere tabi tutmuştur. Sonuç olarak, öğrencilerin arkadaşlarıyla ve öğretmenleriyle etkileşimlerini ön plana alacak şekilde tasarlanmış harmanlanmış öğretim etkinliklerinin ön plana alınması gerektiği bulgusuna ulaşmıştır. Edmodo'nun bu tür etkileşime olanak sağlaması sebebiyle yüz yüze yapılan etkinliklerle harmanlanmasını destekleyici olduğu sonucu elde edilmiştir.

Edmodo'nun önerilen faydalarına rağmen kullanımında özellikle dilinin İngilizce olması, bildirim problemi gibi yazılım kaynaklı sorunları da bulunmaktadır. Kuzgun ve Özdinç (2017) çalışmalarında Edmodo'nun kullanabilirliğini Edmodo kullanımında deneyimli, az deneyimli ve deneyimsiz olarak belirledikleri toplam altı BÖTE bölümü öğrencisi ile değerlendirmişlerdir. Yaptıkları gözlem ve sistem kullanabilirlik ölçeği bulgularına göre Edmodo'nun orta seviyede bir kullanılabilirliğe sahip olduğu sonucuna varmışlar ve Türkçe dil desteği, yönlendirme desteği ve Türkçe yardım paneli özelliklerinin desteklenmesi gerektiğini belirtmişlerdir.

$\mathrm{Bu}$ çalışmada Edmodo, matematik öğretmen adaylarının Matematik Öğretim Programı dersinde kullanımına açılmış ve bu platformla ilgili olumlu/olumsuz görüşleri ve önerileri ortaya çıkarılmaya çalışılmıştır. Bu çalışmanın yürütüldüğü üniversitede seçmeli bir ders olarak okutulan Matematik Öğretim Programı dersi, 4. Sınıfın ikinci döneminde verilmektedir. Bu dersin amacı öğrencilerin programın içeriği, amaçları, vizyonu, yöntem ve stratejileri gibi unsurlarını öğrenmesi ve aynı zamanda eski ve güncel program arasındaki farklılık ve değişimlerin karşılaştırılarak öğrenilmesini sağlamaktır.

En son 2013 yllında yayımlanan matematik öğretim programı 2018 yılında yeniden güncellenmiştir. Beyendi'ye (2018) göre 2018 öğretim programı 2013 
programının aksine değerler konusunu derinlemesine ele almış, kazanım sayısında 2013' e göre azalma olmuşken ünite sayısında artış olmuştur. Her iki programın da tematik, öğrenci merkezli ve ünite temelli olduğunu bildiren Beyendi (2018), eski programa göre 2018 öğretim programında yine bir sadeleşme yapıldığını bildirmiştir.

Milli Eğitim Bakanlığı (2018) yayınladığı matematik öğretim programında, öğretmenlerin programın amaç ve kazanımlarını gerçekleştiren ve uyarlama yapan bireyler olduğunu belirtmiştir. Buna ek olarak, programdaki her bir kazanımın öğrenci gelişimini başka alanlarda da yakından etkileyebileceğini ve bu durumda en büyük rolün öğretmenlere düştüğünü belirtmiştir.

$\mathrm{Bu}$ çalışmada öğretmen adaylarının değişen öğretim programı ile ilgili farkındalıklarını arttırmak ve yapılan değişiklikleri görmelerini sağlamak için 2013 ve 2018 programlarını karşılaştırmaları istenmiştir. Bu etkinliği alan yazında faydalarından bahsedilen, öğrencilerin oldukça olumlu bir görüş belirttikleri bir sosyal paylaşım platformu olan Edmodo'da yapmaları ve tüm bu etkinlikle ilgili görüşlerini ortaya çıkarmak amaçlanmıştır. Bu sebeple onlardan işbirlikli bir ortamda buldukları değişiklikleri Edmodo sistemi üzerinden paylaşmaları istenmiştir. Ayrıca ders kapsamında Edmodo platformu üzerinden ödev ve quizlere de yer verilmiştir. Dönem sonunda Edmodo platformunun ders kapsamında bu etkinlikler çerçevesinde kullanılması ile ilgili görüşleri ortaya çıkarılmaya çalışılmıştır.

\section{Yöntem}

\section{Katılımcılar}

$\mathrm{Bu}$ çalışma, 2017-2018 eğitim öğretim yılı bahar döneminde tamamlanmıştır. Katılımcılar bir devlet üniversitesinin ilköğretim matematik öğretmenliği bölümünde, belirtilen dönemde Matematik Öğretim Programı dersini alan, 4. Sınıfta öğrenim gören 42 öğretmen adayıdır. Amaçlı örnekleme ile seçilen katılımcılar ölçüt olarak Edmodo sosyal eğitim platformunun kullanıldığı Matematik Öğretim Programı dersini alan tüm öğrencilerden oluşmaktadır. Öğrencilere ait demografik bilgiler aşağıdaki tabloda verilmiştir.

Tablo 1.

Demografik Bilgiler

\begin{tabular}{|c|c|c|c|c|c|c|c|}
\hline \multirow{6}{*}{$\underset{\nearrow}{\mathbb{Z}}$} & & $f$ & $\%$ & \multirow{6}{*}{ 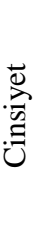 } & \multirow{3}{*}{$\mathrm{K}_{1 \mathrm{Z}}$} & \multirow{2}{*}{$\begin{array}{l}f \\
22\end{array}$} & \multirow{2}{*}{$\begin{array}{c}\% \\
\% 52\end{array}$} \\
\hline & 21 & 8 & $\% 19$ & & & & \\
\hline & 22 & 15 & $\% 36$ & & & & \\
\hline & 23 & 15 & $\% 36$ & & Erkek & 20 & $\% 48$ \\
\hline & 24 & 1 & $\% 2$ & & & & \\
\hline & Belirtmemiş & 3 & $\% 7$ & & & & \\
\hline
\end{tabular}




\section{Araştırma Deseni}

$\mathrm{Bu}$ çalışmada nitel araştırma yöntemlerinden durum çalışması deseni kullanılmıştır. Durum çalışmalarında bir durum derinliğine araştırılır ve bireyler, olaylar ve ortam gibi etkenlerin belirli bir durumu nasil etkiledikleri ve etkilendikleri belirlenir (Yıldırım \& Şimşek, 2013, s.83). Bu çalışma kapsamında öğretmen adayları geleneksel bir öğretimin dışında, teknoloji ile iç içe bir ortamda eğitsel bir sosyal medya platformu kullanarak bir dönemlik eğitim sürecini tamamlamış ve bu kapsamda görüşleri sorulmuştur.

\section{Veri Toplama Süreci}

Matematik Öğretim Programı dersi 14 haftalık bahar dönemi süresince okutulmaktadır. Dersin ilk haftasında öğrencilerden Edmodo sistemine kayıt olmaları ve bu sistemde açılan Matematik Öğretim Programı dersine sistem tarafindan belirlenen giriş kodunu kullanarak giriş yapmaları istenmiştir. Dersin öğretim üyesi tarafindan öncelikle MEB tarafından 2013 ve 2018 yıllarında yayımlanan Matematik öğretim programları sisteme yüklenmiş ve öğrencilerden derste kullanmak üzere bu programların çıktısını almaları istenmişstir. İlk üç hafta programın vizyonu, misyonu, hedef ve kazanımlar gibi temel kavramlar tanıtılmıştır. Sonraki haftalarda öğrencilerden öncelikle 2'şer ve 3'er kişilik gruplar halinde bu programları ünite ünite, kazanım kazanım karşılaştırmaları ve belirlenen bir süre içerisinde buldukları değişimleri Edmodo üzerinden paylaşmaları istenmiştir. Dersin öğretim üyesi, bulunan değişimleri öğrencilerle birlikte sınıf içi tartışma ortamı içerisinde Word belgesi üzerinden tablolaştırmış ve bulunan benzerlik ve farklılıklar üzerinde durulmuştur. $\mathrm{Bu}$ karşılaştırma listeleri, ders sonunda öğretim üyesi tarafından tüm sınıfın kullanımı için Edmodo kütüphanesinde paylaşılmıştır. Ders dışı etkinlikler olarak kazanımlar üzerinde araştırma ve uygulama yapmalarını gerektiren ödevler yapmaları ve bu ödevleri Edmodo sistemi üzerinden belirlenen bir süre içerisinde paylaşmaları istenmiştir. Dönem sonuna doğru Edmodo üzerinden quizler yapılarak öğrencilerin dersle ilgili kendilerini test etmeleri sağlanmıştır. Dönem sonunda öğrencilerden çoktan seçmeli ve açık uçlu sorulardan oluşan yarı yapılandırılmış görüşme formunu doldurmaları istenmiştir.

\section{Araştırma Problemleri}

$\mathrm{Bu}$ çalışmada verilerin kodlama aşamasına tema olarak teşkil eden 4 ana araştırma problemi sorulmuştur:

1. Matematik öğretmen adaylarının Edmodo kullanımına ilişkin genel görüșleri nelerdir?

2. Matematik öğretmen adaylarının Edmodo'nun quiz için kullanımına ilişkin görüşleri nelerdir?

3. Matematik öğretmen adaylarının Edmodo'nun karșılaștırma etkinlikleri için kullanımına ilişkin görüşleri nelerdir? 
4. Matematik öğretmen adaylarının Edmodo'nun ödev-mesaj paylaşımı için kullanımına ilişkin görüşleri nelerdir?

\section{Veri Toplama Aracı ve Analiz Yöntemi}

$\mathrm{Bu}$ çalışmada veri toplama aracı, araştırmacılar tarafindan geliştirilen ve uzman görüşü alınarak son şekli verilen toplam 18 tane sorudan oluşmaktadır. Seçenekli sorular öğretmen adaylarının yaşı, cinsiyeti, Edmodo kullanma sıklıkları, Edmodo’ya erişmek için hangi cihazı kullandıkları (masaüstü bilgisayar, cep telefonu vs.) gibi bilgilerini açığa çıkaran sorulardan oluşmaktadır. Ayrıca öğretmen adaylarının Edmodo ile ilgili düşüncelerini almak üzere oluşturulan 5 tane likert tipi soru yine bu kısımda kullanılmıştır. Örneğin, Edmodo'nun derse olan ilgilerini arttırıp arttırmadığı, öğretmen olduklarında bu tür platformları kullanıp kullanmayacaklarına ilişkin görüşleri bu sorular ile belirlenmeye çalışılmıştır. 9 tane açık uçlu soru ise öğretmen adaylarının ders kapsamında Edmodo kullanımı ile ilgili genel görüşlerini açığa çıkarmak üzere olduğu gibi quiz kullanımı, öğretim programları karşılaştırma etkinlikleri ve ödev-mesaj paylaşımı ile ilgili görüşlerini de almak için hazırlanmıştır.

Çoktan seçmeli sorular için frekans ve yüzdelik kullanılmıştır. Açık uçlu sorulara verilen cevaplar ise Edmodo'da yapılan etkinlikler çerçevesinde betimsel analiz yöntemine göre genel görüşler, quizler, karşılaştırma etkinlikleri ve ödev-mesaj paylaşımı olarak belirlenen dört tematik çerçeve altında kodlanmış ve yorumlanmıştır. Veriler ikinci bir araştırmacı tarafından kodlanmış ve kodlama güvenirliği Miles ve Huberman (1994) tarafından önerilen Görüş Birliği / (Görüş Birliği + Görüş Ayrılı̆̆l) * 100 formülü ile hesaplanmıştır. Sonuç olarak kodlama güvenirliği 0.88 olarak tespit edilmiştir.

\section{Bulgular}

Öğretmen adaylarının Edmodo kullanım bilgileri, Edmodo kullanımı ile ilgili düşüncelerine ilişkin çoktan seçmeli sorulara verdikleri cevaplardan elde edilen veriler şöyle özetlenebilir:

Öğretmen adaylarının Edmodo’yu kullanma sıklığı ve hangi cihazla kullandığına bakıldığında, öğretmen adaylarının çoğunluğu (\%67) haftada en az bir kez Edmodo' yu kullanmaktadır. \%33'lük bir kısmı ise Edmodo'yu sadece gerektiğinde kullandığını belirtmektedir. Ayrıca öğretmen adaylarının tamamının cep telefonu üzerinden Edmodo' yu kullandığı, aynı zamanda iki kişinin bilgisayar üzerinden de giriş yaptığ 1 görülmektedir.

Öğretmen adaylarının Edmodo kullanımı ile ilgili düşüncelerine ilişkin çoktan seçmeli sorulara verdikleri cevaplar Tablo 2'de özetlenmiştir. 
Tablo 2.

EDMODO'nun Kullanımı İle İlgili Düşünceler

\begin{tabular}{|c|c|c|c|c|c|c|c|c|c|c|}
\hline \multirow[t]{2}{*}{$\begin{array}{l}\text { Düşüncel } \\
\text { er }\end{array}$} & \multicolumn{2}{|c|}{$\begin{array}{l}\text { Gelecekte } \\
\text { kullanmak } \\
\text { isterim }\end{array}$} & \multicolumn{2}{|c|}{$\begin{array}{l}\text { Eğitimde } \\
\text { teknoloji } \\
\text { entegrasyonu } \\
\text { fikrime katkıda } \\
\text { bulundu }\end{array}$} & \multicolumn{2}{|c|}{$\begin{array}{l}\text { Derse } \\
\text { kat1lımımı } \\
\text { arttırdı }\end{array}$} & \multicolumn{2}{|c|}{$\begin{array}{l}\text { Ders daha } \\
\text { ilginç bir } \\
\text { hale geldi }\end{array}$} & \multicolumn{2}{|c|}{$\begin{array}{l}\text { Başka } \\
\text { derslerde de } \\
\text { kullanılmalı }\end{array}$} \\
\hline & $f$ & $\%$ & $f$ & $\%$ & $\mathrm{f}$ & $\%$ & $\mathrm{f}$ & $\%$ & $\mathrm{f}$ & $\%$ \\
\hline *K. Hayır & 1 & $\% 2$ & - & - & - & - & 1 & $\% 2$ & - & - \\
\hline Hayır & 3 & $\%$ & - & - & 2 & $\% 5$ & 1 & $\% 2$ & 3 & $\% 7$ \\
\hline Kismen & 8 & $\% 19$ & 2 & $\% 5$ & 7 & $\% 17$ & 10 & $\% 24$ & 4 & $\% 10$ \\
\hline Evet & 20 & $\% 48$ & 18 & $\% 43$ & 17 & $\% 40$ & 17 & $\% 40$ & 20 & $\% 48$ \\
\hline K. Evet & 10 & $\% 24$ & 22 & $\% 52$ & 16 & $\% 38$ & 13 & $\% 31$ & 15 & $\% 36$ \\
\hline
\end{tabular}

*K. = Kesinlikle anlamındadır

Tablo 2'de yer alan veriler incelendiğinde öğretmen adaylarının çoğunluğunun Edmodo kullanımının eğitimde teknoloji entegrasyonu ile ilgili fikirlerine katkıda bulunduğunu (\%96), derse katılımlarını (\%78) arttırdığını ve dersin daha ilginç hale (\%71) geldiğini düşündükleri görülmektedir. Ayrıca öğretmen adaylarının büyük bir kısmının Edmodo'nun başka derslerde de kullanılmasını talep ettikleri (\%82) ve gelecekte kendilerinin de derslerinde bu uygulamayı kullanmak istedikleri (\%72) göze çarpmaktadır.

Öğretmen adaylarıyla yapılan görüşmelerden açık uçlu sorulara verdikleri cevaplar Edmodo'da yapılan etkinlikler çerçevesinde genel görüşler, quizler, karşılaştırma etkinlikleri ve ödev-mesaj paylaşımı temaları altında kodlanmış ve yorumlanmıştır. Elde edilen veriler olumlu, olumsuz ve öneriler şeklinde sınıflandırılmış ve tablolaştırılmıştır.

\section{Edmodo Kullanımına İlişkin Genel Görüşler}

Öğretmen adaylarının genel olarak Edmodo kullanımına ilişkin olumlu görüşleri Tablo 3'te yer almaktadır. Tablo 3'te yer alan veriler incelendiğinde, öğretmen adaylarının Edmodo'nun kullanımını en çok erişim kolaylığı (\%47.6), derse katılımı $(\% 40.5)$ ve derse ilgiyi arttırma (\%40.5) hususlarında olumlu buldukları görülmektedir. Bunların dışında en çok dile getirilen olumlu görüşler ders notlarına erişim kolaylığı, iletişim kolaylığı, zaman tasarrufu sağlaması, eğlenceli olması ve eğitimde teknoloji deneyimi yaşatmasıdır.

Tablo 3.

Genel Olarak EDMODO Kullanımına İlişkin Olumlu Görüşler

\begin{tabular}{llllll}
\hline Kodlar & $\mathrm{f}$ & $\%$ & Kodlar & f & $\%$ \\
\hline Erişim kolaylığı & 20 & $\% 47.6$ & Öğrenmeye destek & 4 & $\% 9.5$ \\
Derse katılımı arttırma & 17 & $\% 40.5$ & Araştırmaya teşvik etme & 3 & $\% 7.1$
\end{tabular}




\begin{tabular}{|c|c|c|c|c|c|}
\hline Derse ilgiyi artırma & 17 & $\% 40.5$ & Sorumluluk bilinci & 3 & $\% 7.1$ \\
\hline Ders notlarına erişim & 9 & $\% 21.4$ & Ders takibi & 3 & $\% 7.1$ \\
\hline İletişim kolaylığ & 8 & $\% 19$ & Kalıcı öğrenme & 2 & $\% 4.8$ \\
\hline Zaman tasarrufu & 7 & $\% 16.7$ & Kağıt tasarrufu & 2 & $\% 4.8$ \\
\hline Eğlenceli & 7 & $\% 16.7$ & Ders içi etkileşim & 1 & $\% 2.4$ \\
\hline $\begin{array}{l}\text { Eğitimde } \\
\text { deneyimi }\end{array}$ & 7 & $\% 16.7$ & Not tutmama & 1 & $\% 2.4$ \\
\hline Faydalı & 6 & $\% 14.3$ & $\begin{array}{l}\text { Teknoloji önyargısını } \\
\text { kırma }\end{array}$ & 1 & $\% 2.4$ \\
\hline Etkili öğrenme & 5 & $\% 11.9$ & Derse hazırlıklı gelme & 1 & $\% 2.4$ \\
\hline Teknoloji çağına uygun & 4 & $\% 9.5$ & & & \\
\hline
\end{tabular}

Aşağıda Ö9 ve Ö32 öğretmen adaylarının görüşmelerinden yapılan alıntılar bu duruma örnek teşkil etmektedir.

Ö9: Sınıf içi kullanımda derse aktif katılım oranını artırıyor. Sınıf dışı kullanımda da notların pdf'sine, notlara rahatlıkla ulaşabiliyorum. Gayet verimli ve zamanımı almıyor.

Ö32: Ders daha eğlenceli ve verimli geçti. Geleneksel bir öğretimden uzak, teknolojiden yararlanılarak işlenen bir ders oldu.

Etkili ve kalıcı öğrenmeyi sağlaması, teknoloji çağına uygun olması, kişiyi araştırmaya teşvik etmesi, sorumluluk bilinci kazandırması, kağıt tasarrufu sağlaması, ders takibini kolaylaştırması, ders içi etkileşimi arttırması ve teknoloji ön yargısını kırması daha az sıklıkta dile gelen diğer olumlu görüşlerden bazılarıdır.

$\mathrm{Bu}$ olumlu görüşlerin yanında öğretmen adaylarının Edmodo’nun kullanımına ilişkin yaşadıkları zorluklar da bulunmaktadır. Bu zorluklar Tablo 4 'te özetlenmiştir.

Tablo 4.

Genel Olarak EDMODO Kullanımına İlişkin Yaşanan Zorluklar

\begin{tabular}{lll}
\hline Kodlar & $\mathrm{f}$ & $\%$ \\
\hline Zorluk yaşamadım & 8 & $\% 19$ \\
İngilizce olması & 15 & $\% 35.7$ \\
İnternet problemi & 6 & $\% 14.3$ \\
Grup kodu güncellemeleri & 5 & $\% 11.9$ \\
Bildirim gelmemesi & 5 & $\% 11.9$ \\
Zaman alıcı & 4 & $\% 9.5$ \\
Zamanla zorluğu aşma & 4 & $\% 9.5$ \\
Yeniden kayıt olma & 3 & $\% 7.1$ \\
Teknoloji kullanma becerisi eksikliği & 2 & $\% 4.8$ \\
Kütüphaneyi bulamama & 1 & $\% 2.4$ \\
\hline
\end{tabular}

Öğretmen adaylarının bir kısmı Edmodo kullanımında zorluk yaşamadıklarını (\%19) belirtmektedir. Bunun yanında en sık dile getirilen zorluklar Edmodo'nun 
mobil uygulamadaki dilinin İngilizce olması (\%35.7) ve internet bağlantısında (\%14.3) sorun yaşamalarıdır. Aşağıda Ö35 ve Ö6 öğretmen adaylarının görüşmelerinden yapılan alıntılar bu duruma örnek teşkil etmektedir.

Ö35: İngilizce olduğu için çok fazla zorlandım. Türkçe olsa anlayarak ve yardım almadan kolay şekilde kullanabilirim.

Ö6: Sadece internet olmadığında bağlanamadım. Böyle bir sıkıntı yaşadım. Bir de arada mesajlar geç geliyordu.

Öğretmen adayları bunlara ek olarak grup kodu güncellemeleri, bildirim gelmemesi, yeniden kayıt olma, kütüphaneyi bulamama gibi zorluklar yaşadıklarını belirtmektedir. Ayrıca Edmodo kullanımını zaman alıcı bulan, yaşadıkları zorluğu kendi teknoloji kullanma beceri eksikliklerine dayandıran öğretmen adayları da mevcuttur. Öğretmen adaylarının bir kısmı ise başlangıçta yaşadıkları zorlukları zamanla tecrübe kazandıkça aştıklarını belirtmektedir.

Öğretmen adaylarının Edmodo kullanımına ilişkin genel önerileri Tablo 5'te yer almaktadır.

Tablo 5 .

Genel Olarak EDMODO Kullanımına İlişkin Öneriler

\begin{tabular}{lll}
\hline Kodlar & $\mathrm{f}$ & $\%$ \\
\hline Tavsiye ederim & 35 & $\% 83.3$ \\
Kullanımı yaygınlaştırılmalı & 7 & $\% 16.7$ \\
Zaman kullanımına dikkat edilmeli & 4 & $\% 9.5$ \\
Öğretmen olarak kullanırım & 2 & $\% 4.8$ \\
Bilgisayar laboratuvarında işlenmeli & 1 & $\% 2.4$ \\
İnternet bağlantısı problemi çözülmeli & 1 & $\% 2.4$ \\
Kullanma sıklığı azaltılmalı & 1 & $\% 2.4$ \\
\hline
\end{tabular}

Tablo 5 incelendiğinde, öğretmen adaylarının büyük bir çoğunluğunun (\%83.3) Edmodo'nun bu ders kapsamında kullanılmaya devam etmesini tavsiye ettiği görülmektedir. Bunun yanında farklı derslerde de kullanılarak kullanımının yaygınlaştırılmasını öneren (\%16.7), ileride öğretmen olduğunda Edmodo'yu derslerinde kullanacağını (\%4.8) belirten öğretmen adayları da mevcuttur. Ö19 öğretmen adayının görüşmesinden yapılan alıntı bu durumu yansıtmaktadır.

Ö19: Kesinlikle tavsiye ederim. Eğer ilerde benim için de şartlar ve imkânlar uygun olursa, Edmodo'yu derslerim kapsamında kullanmayı düşünüyorum.

Daha iyi bir kullanım için zaman kullanımına dikkat edilmesi, dersin bilgisayar laboratuvarında işlenmesi, internet bağlantısı probleminin çözülmesi ve dikkat çekiciliğini yitirmemesi için kullanma sıklığının azaltılması öğretmen adaylarının dile getirdiği diğer önerilerdir. 


\section{Edmodo'da Quiz Kullanımına İlişkin Görüşler}

Öğretmen adaylarının Edmodo’da quiz kullanımına ilişkin olumlu görüşleri Tablo 6'da özetlenmiştir.

Tablo 6 .

EDMODO’da Quiz Kullanımına İlişkin Olumlu Görüşler

\begin{tabular}{lll}
\hline Kodlar & $\mathrm{f}$ & $\%$ \\
\hline Kendini değerlendirme & 13 & $\% 31$ \\
Faydalı & 10 & $\% 23.8$ \\
Güzel bir uygulama & 7 & $\% 16.7$ \\
Sinıfın genel durumunu görme & 5 & $\% 11.9$ \\
Dönüt alma & 5 & $\% 11.9$ \\
Ilgiyi artırma & 5 & $\% 11.9$ \\
Kullanışlı & 4 & $\% 9.5$ \\
Bilginin pekişmesi & 4 & $\% 9.5$ \\
Katılımın artması & 4 & $\% 9.5$ \\
Geleneksel dışı & 3 & $\% 7.1$ \\
Kağıt tasarrufu & 3 & $\% 7.1$ \\
Daha iyi öğrenme & 3 & $\% 7.1$ \\
Zaman tasarrufu & 2 & $\% 4.8$ \\
Uzaktan eğitim & 2 & $\% 4.8$ \\
Zaman sınırı & 2 & $\% 4.8$ \\
Puanını öğrenme & 1 & $\% 2.4$ \\
Derse hazırlıklı gelme & 1 & $\% 2.4$ \\
Kalıcı öğrenme & 1 & $\% 2.4$ \\
Pozitif sınıf atmosferi & 1 & $\% 2.4$ \\
Sıkıcılığı engelleme & 1 & $\% 2.4$ \\
Stresi engelleme & 1 & $\% 2.4$ \\
Soru çözümünün artması & 1 & $\% 2.4$ \\
\hline
\end{tabular}

Tablo 6 incelendiğinde, öğretmen adaylarının Edmodo' da quiz kullanımını faydalı (\%23), güzel (\%16.7) ve kullanışlı (\%9.5) buldukları görülmektedir. Quiz için kullanımda öğretmen adaylarının en çok hoşuna giden husus kendilerini değerlendirmelerini sağlamasıdır (\%31). Bunun yanında sınıfın genel durumunu görme, hızlı bir şekilde dönüt alma ve ilgiyi arttırması (\%11.9) en çok bahsedilen olumlu yönlerden diğerleridir. Ö7 öğretmen adayının görüşmesinden yapılan alıntı bunu yansitmaktadir.

Ö7: Quiz kullanımlarını çok faydalı buldum. Kendimi görmemi sağladı. Yanlışlarımı düzeltmemi sağladı. Soru çeşitlerini görmemi sağladı. Genel durumu göstermesi ve değerlendirme grafikleri durumumuzu görmemizi sağladi. 
Ayrıca öğretmen adayları Edmodo’da quiz yapıldığında katılımlarının arttığını, bilgilerinin pekiştiğini, daha iyi öğrendiklerini, zamandan ve kağıttan tasarruf ettiklerini dile getirmektedir.

Öğretmen adayları quiz için kullanımıyla ilgili herhangi bir olumsuz görüş dile getirmemiştir. Edmodo'da quiz kullanımına ilişkin önerileri ise Tablo 7'de yer almaktadir.

Tablo 7.

EDMODO’da Quiz Kullanımına İlişkin Öneriler

\begin{tabular}{lll}
\hline Kodlar & f & $\%$ \\
\hline Quiz sayısı arttırılmalı & 17 & $\% 40.5$ \\
Cevap Anahtarı görülebilmeli & 2 & $\% 4.8$
\end{tabular}

Tablo 7 incelendiğinde öğretmen adaylarının yarısına yakınının quiz sayısının arttırılmasını (\%40.5), çok az bir kısmının ise (\%4.8) cevap anahtarının quiz sonrasında görülmesini (\%4.8) istedikleri görülmektedir. Ö15 öğretmen adayından yapılan alıntı bu durumu yansitmaktadir.

Ö15: Quizlerin arttırılması taraftarıyım. Daha kalıcı öğrenmeler olacaktır...

\section{EDMODO’da 2013-2018 Öğretim Programlarını Karşılaştırma Etkinliklerine İlişkin Görüşler}

Öğretmen adaylarının Edmodo'da yapılan 2013-2018 öğretim programları karşılaştırma etkinliklerine ilişkin olumlu görüşleri Tablo 8'de özetlenmiştir.

Tablo 8.

EDMODO’da Karşılaştırma Etkinliklerine İlişkin Olumlu Görüşler

\begin{tabular}{llllll}
\hline Kodlar & $\mathrm{f}$ & $\%$ & Kodlar & $\mathrm{f}$ & $\%$ \\
\hline Ders notlarına erişim & 17 & $\% 40.4$ & Kalıcı öğrenme & 2 & $\% 4.8$ \\
Faydalı & 12 & $\% 28.6$ & Yorum yapma becerisi & 1 & $\% 2.4$ \\
İşbirliği & 9 & $\% 21.4$ & Yaparak yaşayarak öğrenme & 1 & $\% 2.4$ \\
Katılımı arttırma & 6 & $\% 14.3$ & Eğlenceli & 1 & $\% 2.4$ \\
Daha iyi öğrenme & 4 & $\% 9.5$ & Zamanın verimli kullanımı & 1 & $\% 2.4$ \\
Kullanışlı & 2 & $\% 4.8$ & Farkı görebilme & 1 & $\% 2.4$ \\
Eksiklerini görme & 2 & $\% 4.8$ & & & \\
\hline
\end{tabular}

Tablo 8 incelendiğinde, öğretmen adaylarının Edmodo'da yapılan karşılaştırma etkinliklerini faydalı (\%28.6) ve kullanışlı (\%4.8) bulduğu görülmektedir. Öğretmen adaylarının yarısına yakını ders notlarına erişim (\%40.4) açısından Edmodo'da yapılan karşılaştırma etkinliklerini olumlu bulmaktadır. İşbirliği ortamının oluşması (\%21.4), katılımı arttırması (\%14.3) ve daha iyi öğrenmelerin gerçekleşmesi (\%9.5) dile getirilen diğer olumlu yönlerdir. Ö3 öğretmen adayından alıntı bunu yansitmaktadir. 
Ö3: Çok faydalı oldu bence 2013 ve 2018 tablosu oluşturduk ve herkes bulduğu farkları mesaj olarak gönderdi, düzenlemeler sonucu tablo tamamlanıp yine bize ulaştırıldı bu şekilde olması ulaşım kolaylığı ve anlaşılırlığı artırdı.

Ayrıca eksiklerini görme, kalıcı öğrenme, yorum yapma becerisini geliştirme, eğlenceli hale getirme öğretmen adaylarının daha az sıklıkta bahsettikleri olumlu görüşlerden bazılarıdır.

Öğretmen adaylarının Edmodo'da yapılan karşılaştırma etkinliklerine ilişkin çok az sıklıkta da olsa olumsuz görüşleri bulunmaktadır. Bunlar Tablo 9'da yer almaktadır.

Tablo 9.

EDMODO'da Karşılaştırma Etkinliklerine İlişkin Olumsuz Görüşler

\begin{tabular}{lcl}
\hline Kodlar & $\mathrm{f}$ & $\%$ \\
\hline Zaman kaybı & 3 & $\% 7.1$ \\
Gereksiz & 3 & $\% 7.1$ \\
Katılımın sağlanamaması & 3 & $\% 7.1$ \\
İnternet problemi & 1 & $\% 2.4$ \\
\hline
\end{tabular}

Tablo 9 incelendiğinde, öğretmen adaylarının az bir kısmının (\%7.1) Edmodo’da yapılan karşılaştırma etkinliklerini zaman kaybı ve gereksiz olarak gördüklerini ve katılımın sağlanamadığını düşündükleri görülmektedir. Ö7 öğretmen adayının görüşmesinden yapılan alıntı bu durumu yansıtmaktadır.

Ö7: Zaman kaybı haricinde faydalı olduğunu düşünüyorum...

Öğretmen adaylarının Edmodo'da yapılan karşılaştırma etkinlikleri için önerileri Tablo 10'da yer almaktadır.

Tablo10.

EDMODO'da Karşılaştırma Etkinliklerine İlişkin Öneriler

\begin{tabular}{lll}
\hline Kodlar & $\mathrm{f}$ & $\%$ \\
\hline Kağı üzerinde olmalı & 3 & $\% 7.1$ \\
Karşılaştırma etkinlikleri puanlı olmalı & 2 & $\% 4.8$ \\
Etkinlikler ödev olmalı & 1 & $\% 2.4$ \\
Derste soru çözülmeli & 1 & $\% 2.4$ \\
Paylaşım daha hızlı olmalı & 1 & $\% 2.4$ \\
\hline
\end{tabular}

Öğretmen adayları Edmodo üzerinden yapılan karşılaştırma etkinliklerinin kağıt üzerinde olmasını (\%7.1), katılımın artması için puanlı olmasını (\%4.8) önermektedir. Ö3 öğretmen adayından yapılan alıntı buna bir örnektir.

Ö3: ... Uygulamalarda karşılaştırma yapma puanlı olmalı yoksa sınıfta bazıları katılım sağlamıyor 
Ayrıca sadece bir öğretmen adayı karşılaştırma etkinliklerinin ödev olarak verilmesini, derste daha çok soru çözülmesini ve etkinlik sırasında katılımcıların daha hızlı paylaşım yapmalarını önermektedir.

\section{EDMODO’da Ödev ve Mesaj Paylaşımına İlişkin Görüşler}

Öğretmen adaylarının Edmodo'nun ödev-mesaj paylaşımı için kullanımına ilişkin olumlu görüşleri Tablo 11'de yer almaktadır.

Tablo 11.

\section{EDMODO’da Ödev ve Mesaj Paylaşımına İlişkin Olumlu Görüşler}

\begin{tabular}{lll}
\hline Kodlar & $\mathrm{f}$ & $\%$ \\
\hline İletişim kolaylığı & 14 & $\% 33.3$ \\
Ödev bildirimi & 9 & $\% 21.4$ \\
Faydalı & 6 & $\% 14.3$ \\
Esnek zaman & 6 & $\% 14.3$ \\
Zaman sınırı & 4 & $\% 9.5$ \\
Puanını görebilme & 4 & $\% 9.5$ \\
Uzaktan eğitim & 4 & $\% 9.5$ \\
Güzel & 4 & $\% 9.5$ \\
Sorumluluk bilinci kazanma & 4 & $\% 9.5$ \\
Kalıcı öğrenme & 3 & $\% 7.1$ \\
Zaman tasarrufu & 3 & $\% 7.1$ \\
Ödev takibi & 3 & $\% 7.1$ \\
Ödev yapma oranını artırma & 3 & $\% 7.1$ \\
Kullanışlı & 2 & $\% 4.8$ \\
Ödev teslim şekli & 2 & $\% 4.8$ \\
Yaparak yaşayarak öğrenme & 2 & $\% 4.8$ \\
Eğlenceli & 1 & $\% 2.4$ \\
İlgiyi arttırma & 1 & $\% 2.4$ \\
Kağıt tasarrufu & 1 & $\% 2.4$ \\
Ödev anlaşılırlığı & 1 & $\% 2.4$ \\
Dönüt alma & 1 & $\% 2.4$ \\
\hline
\end{tabular}

Tablo 11 incelendiğinde, öğretmen adaylarının Edmodo'nun ödev ve mesaj paylaşımı için kullanımını faydalı (\%14.3), güzel (\%9.5), kullanışlı (\%4.8) buldukları görülmektedir. Öğretmen adaylarının en sık dile getirdikleri olumlu yönler iletişim kolaylığı sağlaması(\%33.3) ve ödev bildiriminin (\%21.4) gelmesidir. Ayrıca esnek zamanlarda (\%14.3), uzaktan eğitim şeklinde (\%9.5), belirli bir zaman sınırı (\%9.5) içerisinde ödevleri yapmanın sorumluluk bilinci kazandırdığ $1(\% 9.5)$ ve ödev yapma oranını arttırdığı (\%7.1) öğretmen adayları tarafından dile getirilmektedir. Ö42 öğretmen adayının görüşmesinden yapılan alıntı buna örnektir.

Ö42: Ödev alışkanlığı kazandırdı. Takıldığım konularda hoca ve arkadaşlarıma mesaj atarak bilgilendim. Bu yüzden ödev ve mesaj paylaşımı çok yararlı. 
Öğretmen adaylarının Edmodo’da ödev ve mesaj paylaşımına ilişkin olumsuz görüşleri Tablo 12'de özetlenmiştir.

Tablo 12.

EDMODO’da Ödev ve Mesaj Paylaşımına İlişkin Olumsuz Görüşler

\begin{tabular}{lll}
\hline Kodlar & $\mathrm{f}$ & $\%$ \\
\hline Bildirim gelmemesi & 5 & $\% 11.9$ \\
Ödeve cevap gönderememe & 2 & $\% 4.8$ \\
Ödev teslim bildiriminin olmaması & 2 & $\% 4.8$ \\
Ödev sayısı fazla & 1 & $\% 2.4$ \\
Fotoğraf ekleme problemi & 1 & $\% 2.4$ \\
Ödev teslim şekli & 1 & $\% 2.4$ \\
\hline
\end{tabular}

Öğretmen adayları bazen ödev ve mesaj bildiriminin gelmemesinden (\%11.9), Edmodo üzerinden ödeve cevap göndermekte zorlanmaktan (\%4.8), ödevin teslim edildiğine dair geri bir bildirim gönderilmemesinden (\%4.8) şikayet etmektedir. Ö4 öğretmen adayının görüşmesinden alınan alıntı bu duruma örnektir.

Ö4: Bazen bildirimler gelmiyor. Ödevler süreli olduğu için kaçırıyoruz...

Ayrıca bir öğretmen adayı ödev sayısını fazla bulduğunu, ödev teslim şeklini beğenmediğini, fotoğraf eklemekte problem yaşadığını belirtmektedir.

Öğretmen adaylarının Edmodo'da ödev ve mesaj paylaşımı için önerileri Tablo 13 'te özetlenmiştir.

Tablo13.

EDMODO’da Ödev ve Mesaj Paylaşımına İlişkin Öneriler

\begin{tabular}{lll}
\hline Kodlar & $\mathrm{f}$ & $\%$ \\
\hline Ödev raporları tüm sınıfa açık olmalı & 3 & $\% 7.1$ \\
Ödevler puanlı olmalı & 3 & $\% 7.1$ \\
Ödev sayısı artmalı & 1 & $\% 2.4$ \\
Kağıt üzerinde olmalı & 1 & $\% 2.4$ \\
\hline
\end{tabular}

Öğretmen adayları teslim edilen ödevin tüm sınıf tarafindan görülebilmesini (\% 7.1), ödevlerin puan olarak final notunu etkilemesini (\%7.1), ödev sayısının artmasını (\%2.4) ve kağıt üzerinde olmasını (\%2.4) önermektedir. Ö37 öğretmen adayının görüşmesinden yapılan alıntı bu duruma örnektir.

Ö37: Bence verilen ödevlerin cevaplarını sadece öğretmenimiz değil de herkes görebilseydi ve herkes olumlu-olumsuz eleştiri yapabilseydi daha etkili olurdu.

\section{Tartışma, Sonuç ve Öneriler}

$\mathrm{Bu}$ çalışma bir devlet üniversitesinin ilköğretim matematik öğretmenliğinde öğrenim gören 42 ( 22 kız, 20 erkek) öğretmen adayı ile gerçekleştirilmiştir. Öğretmen adayları ders çerçevesinde Edmodo sosyal paylaşım platformunu kullanmışlar ve dönem 
sonunda bu platformla ilgili görüşleri alınmıştır. Alınan veriler derste yapılan etkinlikler çerçevesinde ve Edmodo'nun genel olarak kullanılmasıyla ilgili olarak dört tema altında toplanmış ve betimsel analiz yöntemi ile yorumlanmıştır.

Araştırma bulgularına göre öğretmen adayları Edmodo kullanımını genel olarak en çok erişim kolaylığı sağlaması, derse katılımı ve ilgiyi arttırması açısından olumlu bulmuşlardır. Bu sonuç alan yazındaki çalışmalarla uyum göstermektedir (Hamutoğlu \& Kıyıcı, 2017). İletişim kolaylığı ve zaman tasarrufu sağlaması, dersi eğlenceli hale getirmesi ve eğitimde teknoloji deneyimi yaşatmasını da ayrıca olumlu olarak gördüklerini belirtmişlerdir. Öğretmen adayları ayrıca Edmodo kullanımının yaygınlaştırılması önerisinde bulunmuş ve bu sonuç yine Hamutoğlu ve Kıyıcı (2017)'nın çalışmalarında da ortaya çıkan bir öneridir.

Öğretmen adayları Edmodo kullanımında genel olarak en çok zorluk yaşadıkları durumlar olarak bu platformun cep telefonu uygulamasının İngilizce olmasını ve internet bağlantısı problemini belirtmişlerdir. Son yıllarda Edmodo ile yapılan çalışmalarda öğrencilerle yapılan görüşmelerde uygulamanın dilinin İngilizce olmasının (Kazez \& Bahçeci, 2016; Kuzgun \& Özdinç, 2017) ve internet erişim sorununun (Baştuğ, Solmaz, Kaledibi \& İşbulan, 2016) bu platformla ilgili bir problem olarak bildirildiği görülmektedir. Ayrıca bu çalışmada öğretmen adayları bildirim gelmemesi ve şifrelerini unutmaları durumunda yeniden kayıt yaptırmaları esnasında grup kodunun sürekli güncellenmesi nedeniyle zorluk yaşadıklarını belirtmişlerdir.

Öğretmen adayları görüşme sorularına Edmodo'da quiz kullanımı ile ilgili en çok kendilerini değerlendirebilmelerini, sınıfin genel durumunu pasta grafik şeklinde görebilmelerini ve dönüt alabilmeyi olumlu olarak gördüklerini belirtmişlerdir. İlköğretim öğrencileri ile yapılan çalışmalarda da (Dere, Yücel \& Yalçınalp, 2016) benzer sonuçlar alındığı dikkate alınırsa bu sonucun Edmodo'ya genellenebileceği sonucuna varılabilir. Edmodo'nun quizlerin cevap anahtarlarını göstermemesini olumsuz olan tek yönü olarak belirtmişlerdir. Öğretmen adaylarının yaklaşık yarısı Edmodo'nun tekrar ders kapsamında kullanılması durumunda quiz sayısının arttırılmasını önermişlerdir.

Öğretmen adaylarının Edmodo'da 2013-2018 öğretim programlarının karşılaştırma etkinliklerinin yapılmasına ilişkin en çok olumlu gördükleri yönü, bu programların derste karşılaştırılarak çıkarılan notların Edmodo'da paylaşılmasını ve böylece notlara erişebilmeleri olarak belirtmişlerdir. Bu bulgu, ders notlarına erişimi Edmodo'nun olumlu bir yönü olarak öğrencilerden görüş alan Kazez ve Bahçeci (2016)'nin bulgularıyla örtüşmektedir. Yine bu karşılaştırmaların işbirliği ile yapılmasını en çok olumlu gördükleri yön olarak belirtmişlerdir. Ayrıca öğretmen adayları bu platformda yapılan karşılaştırma etkinliklerinin derse olan katılımı arttırdığını ve böylece onların daha iyi öğrenmelerini sağladığını düşünmektedir. Yine bu sonuç alan yazındaki diğer çalışmalarla örtüşmektedir (Dere, Yücel \& Yalçınalp, 2016; Hamutoğlu \& Kıyıc1, 2017). Az sayıda öğretmen adayı, karşılaştırma 
etkinliklerinin Edmodo üzerinde yapılmasının zaman kaybı ve gereksiz olduğunu ve bu etkinliklerin Edmodo yerine kağıt üzerinde yapılması gerektiğine vurgu yapmışlardır.

Bulgular ayrıca öğretmen adaylarından bazılarının ödev için uygun görmeyen ve ödev sayısının azaltılması gerektiğini belirttikleri görülmüştür. $\mathrm{Bu}$ durumun sebebi Dere, Yücel ve Yalçınalp (2016)' in de bulguları ile tutarlı olarak öğretmen adaylarının ödev yapmayı sevmemeleri olabilir.

Edmodo platformunun ödev ve mesaj paylaşımı için kullanılmasının olumlu yönü olarak en çok iletişim kolaylığı sağlaması ve bildirimlerle ödevlerin iletilmesi olarak belirtilmiştir. Edmodo'nun iletişim kolaylığı sağladığı alan yazında yapılan diğer çalışmalarda da görülmektedir (Kazez \& Bahçeci, 2016). Öğretmen adayları Edmodo'da ödev ve mesaj paylaşımı ile ilgili olarak yaşadıkları zorluklara ödev verildiğinde ve teslim edildiğinde bazen bildirimin gelmeyişini örnek olarak vermişlerdir. $\mathrm{Bu}$ durum yazılımsal bir sorun olarak Edmodo'nun mobil uygulamasında görülmektedir. Bazı öğretmen adayları ayrıca ödevleri Edmodo üzerinden gönderme problemini yaşadıklarını belirtmişlerdir. Ödev ve mesaj paylaşımı ile ilgili öneri olarak ödev raporlarının herkes tarafindan görülmesi gerektiğini belirtmişlerdir. Fakat Edmodo'nun ödev paylaşımında sadece öğretmen ve ödevi gönderen öğrencinin görebileceği şekilde tasarlanmış olması bu duruma engel olmakta ve Kazez ve Bahçeci (2016) tarafindan geliştirilmesi gereken bir yönü olarak önerilmektedir. Öğretmen adayları ayrıca yapılan her ödevin puanlandırılmasıyla katılımın daha da artacağını dile getirmektedir.

Bulgular Dere, Yücel ve Yalçınalp (2016)'in çalışması ile de tutarlı bir sonuç göstermektedir. $\mathrm{Bu}$ çalışmada da öğretmen adayları zaman ve mekân sınırlaması olmaksızın ders dokümanlarına ulaşma ve iletişime geçebilmeyi Edmodo’nun olumlu bir yönü olarak gördüklerini belirtmişlerdir.

Sonuç olarak, öğretmen adaylarının çoğunluğu Edmodo platformunun bu ders kapsamında kullanımını tavsiye ettiklerini belirtmektedir. Öğretmen adaylarına göre bu ortam erişim kolaylığı sağlayan, derse katılımı ve ilgiyi arttıran, iletişim kolaylığı ve zaman tasarrufu sağlayan, dersi eğlenceli hale getiren ve eğitimde teknoloji deneyimi yaşatan olumlu bir atmosfere sahiptir. Fakat İngilizce olması, zaman zaman yaşanan internet bağlantısı problemi ve bildirim gelmemesi gibi yazılımsal sorunlar giderilmeli ve kullanımı yaygınlaştırılmalıdır.

\section{Çıkar Çatışması ve Etik Bildirimi}

Yazarlar arasında çıkar çatışması bulunmadığını ve tüm araştırmacıların çalışmaya eşit oranda katkı sunduğunu beyan etmiştir. Yazarlar tüm etik kurallara uyduklarını bildirmiştir.

\section{Kaynakça}

Al-Abri, A., Jamoussi, Y., Kraiem, N., \& Al-Khanjari, Z. (2017). Comprehensive classification of collaboration approaches in E-learning. Telematics and Informatics, 34(6), 878-893. 
Al-Rahmi, W. M., \& Zeki, A. M. (2017). A model of using social media for collaborative learning to enhance learners' performance on learning. Journal of King Saud UniversityComputer and Information Sciences, 29(4), 526-535.

Aldemir, T., Celik, B. \& Kaplan, G. (2018). A qualitative investigation of student perceptions of game elements in a gamified course. Computers in Human Behavior, 78, 235-254.

Alkan, M. F. \& Bardakçı, S. (2017). Ortaöğretim öğrencilerinin sosyal ağlardan öğrenme biçimleri: nitel bir inceleme. Kastamonu Ĕgitim Dergisi, 25(3), 1221-1238.

Balasubramanian, K., Jaykumar, V., \& Fukey, L. N. (2014). A study on "Student preference towards the use of Edmodo as a learning platform to create responsible learning environment". Procedia-Social and Behavioral Sciences, 144, 416-422.

Baştuğ, İ., Solmaz, İ., Kaledibi, F. \& İşbulan, O. (2016, Ekim). 5. ve 6. sınıf öğrencilerinin programlama eğitiminde Edmodo kullanımına yönelik görüşlerinin değerlendirilmesi. 4th International Instructional Technologies \& Teacher Education Symposium: Re-Discover Learning with Digital Learners içinde (ss. 76 - 84). Fırat Üniversitesi, Elazı̆̆. Erişim adresi: https://ittes.org.tr/dosyalar/files/IttesArsivi/2016/fulltext-proceeding-ittes2016.pdf

Beyendi, S. (2018). 2013-2018 ortaokul matematik dersi öğretim programlarının karşılaştırılması. Birey ve Toplum Sosyal Bilimler Dergisi, 8(1), 177-200.

Dere, E., Yücel, Ü. A. \& Yalçınalp, S. (2016). İlköğretim öğrencilerinin eğitsel bir çevrimiçi sosyal ögrenme ortamı olan Edmodo'ya ilişkin görüşleri. Ilköğretim Online, 15(3).

Edmunds, R., Thorpe, M., \& Conole, G. (2012). Student attitudes towards and use of ICT in course study, work and social activity: A technology acceptance model approach. British Journal of Educational Technology, 43(1), 71-84.

Hamutoğlu, N. B. \& Kıyıcı, M. (2017). Bir eğitsel sosyal ăg olarak Edmodo'nun yükseköğretimde kullanımı hakkındaki öğrenci görüşlerinin incelenmesi. Trakya Üniversitesi Eğitim Fakültesi Dergisi, 7(2), 322-343.

Kazez, H. \& Bahçeci, F. (2016). BÖTE bölümü öğretmen adaylarının Edmodo kullanımına dair görüşlerinin incelenmesi. Eğitim ve Öğretim Araştırmaları Dergisi 5(1), 9-20.

Kurt, Ç. S. (2017). Bir harmanlanmış öğrenme deneyimi. Illköğretim Online, 16(2), 860-886.

Kuzgun, H. \& Özdinç, F. (2017). Eğitsel sosyal ağ ortamı Edmodo'nun kullanılabilirliğinin incelenmesi. Kuramsal Eğitimbilim Dergisi, 10(2), 274-297.

McLean, K., Edwards, S., \& Morris, H. (2017). Community playgroup social media and parental learning about young children's play. Computers \& Education, 115, 201-210.

Miles, M. B., \& Huberman, A.M. (1994). Qualitative data analysis : An expanded sourcebook. (2nd Edition). California: SAGE Publications.

Milli Eğitim Bakanlığı (2018). Matematik Öğretim Programı. Erişim adresi: http://mufredat.meb.gov.tr/Programlar.aspx.

Newman, R., Chang, V., Walters, R. J., \& Wills, G. B. (2016). Web 2.0-The past and the future. International Journal of Information Management, 36(4), 591-598. 
O'Reilly, T. (2007, Ağustos). What is Web 2.0? Design patterns and business models for the next generation of software. Erişim adresi: https://mpra.ub.unimuenchen.de/4578/1/mpra_paper_4578.pdf

Porcel, C., Ching López, A., Lefranc, G., Loia, V. \& Herrera Viedma, E. (2018). Sharing notes: An academic social network based on a personalized fuzzy linguistic recommender system. Engineering Applications of Artificial Intelligence, 75, 1-10.

Sarrab, M., Elbasir, M. \& Alnaeli, S. (2016). Towards a quality model of technical aspects for mobile learning services: An empirical investigation. Computers in Human Behavior, 55, 100-112.

Taşgın, A., \& Küçükoğlu, A. (2016). Klinik uygulamaların öğretmen adaylarının öğretmen özyeterlik algılarına etkisi. Çukurova Üniversitesi Eğitim Fakültesi Dergisi, 45(2), 265.

Trust, T. (2017). Motivation, empowerment, and innovation: Teachers' beliefs about how participating in the Edmodo math subject community shapes teaching and learning. Journal of Research on Technology in Education, 49(1-2), 16-30.

Yıldırım, A. \& Şimşek, H. (2013). Sosyal bilimlerde nitel araştırma yöntemleri (Genişletilmiş 9. bask1). Ankara: Seçkin Yayıncılık.

\section{Extended Abstract}

Edmodo, a free to use social networking website, was developed for students, teachers and parents for educational purposes. In this collaborative platform, they can communicate, access to assignments and class notes, and share ideas (Balasubramanian, Jaykumar \& Fukey, 2014; McLean, Edwards and Morris, 2017). Students can get feedbacks and check their grades. Teachers can evaluate students' performances and see general status of their classses. Parents can see their child's status.

Edmodo has been a subject to educational researches (Aldemir, Çelik \& Kaplan, 2018; Edwards \& Morris, 2017). Trust (2017) in his study had 150 teachers use Edmodo and investigated how teachers shaped their learning and teaching practices. Teachers claimed they gained motivation to improve their practices and can better put learner-based and innovative approaches in practice. Edmodo was used with elementary school students (Dere, Yücel \& Yalçınalp, 2016; Solmaz, Kaledibi \& İşbulan, 2016), freshmen in their new literacy course (Hamutoğlu \& Kıyıc1, 2017), sophomores in their graphics and design course (Kazez \& Bahçeci, 2016) and juniors in blended learning (Kurt, 2017). In these studies, Edmodo was found to be supportive for students' learning, provide ease of access to class notes, increase students' interest and motivation to class, and students have positive reaction towards Edmodo.

In this study, to improve pre-service teachers' awareness of the 2018 mathematics curriculum, and have them see changes from 2013 to 2018 curriculum, collaborative learning activities were carried out on a social media platform. For this, Edmodo was selected because of its above-mentioned benefits as a collaborative educational networking site in the literature. 
This study was completed in the spring semester of 2017-2018 academic year in a public university of Turkey. The participants were 42 pre-service mathematics teachers, who took Mathematics Curriculum class in which Edmodo system was used. The participants were selected with a purposive sampling.

The pre-service teachers used Edmodo for the entire semester in mathematics curriculum class. They joined the class on Edmodo with a group code determined by Edmodo. In the first three weeks, the vision, mission, targets and expectations of the curriculum were introduced. Following weeks, the pre-service teachers were asked to compare 2013 and 2018 mathematics curriculums target by target in a group of two or three in class. They then shared similarities and changes between the curriculums on Edmodo. In class discussions, these findings were combined in a word document and shared on Edmodo library by the instructor for their use. Additionally, they were given homework assignments related to the 2018 curriculum, and submitted these assignments before due dates. They took quizzes, prepared by the instructor, towards the end of the semester on Edmodo. At the end of the semester, they were asked to fill out a semi-structured interview questions form for their views about the process. The research question in this study was:

What are mathematics pre-service teachers' views about the use of Edmodo,

1. In general?

2. For quizzes?

3. For curriculum comparison activities?

4. For homework and messaging?

The data collection tool was developed by the researchers and included 18 questions. 4 questions were about demographic information, frequency that they used Edmodo, device with which they logged into Edmodo. 5 Likert-type questions were about whether Edmodo increased their level of interests to the class and they would use Edmodo in the future. 9 open-ended questions were about general thoughts, use of quizzes, curriculum activities, and homework and messaging on Edmodo. The answers to multiple choice questions were analyzed as frequencies and percentages. Open-ended questions were analyzed with a descriptive analysis under four themes: general thoughts, quizzes, comparison activities, and homework and messaging. Intercoder reliability was calculated with the formula by Miles and Huberman (1994): Number of Agreements / (Number of Agreements + Number of Disagreements) * 100 and found to be .88 .

Based on results, $67 \%$ of the pre-service teachers logged in to Edmodo at least once in a week. The reasons to use Edmodo were assignments and tests (93\%), class notes $(86 \%)$ and in-class activities $(83 \%)$. All students used Edmodo with their mobile phones. Two students also used their laptops.

In general, pre-service teachers mostly think Edmodo increases ease of access, class participation and interest to the class. Additionally, it provides ease of 
communication, saves time, makes class fun and provides technology experience in education. They recommend that Edmodo must be used in other classes as well. However, they reported some negative thoughts, too. For example, the language of the mobile Edmodo app is in English, which makes it hard to understand. Internet connection and on-time notification problems were also reported.

For the use of quizzes, pre-service teachers liked it most to evaluate themselves, see general results of class in graphs and get feedback. More than half of the preservice teachers recommended increasing the number of quizzes. Only negative thought about the quizzes was the absence of answer keys on Edmodo.

For the 2013-2018 curriculum comparison activities, they mostly liked it for the class notes shared in the library and were easily accessible for them. Also, making the comparisons collaboratively was a positive side of the platform. They think that these activities have increased the in-class participation, and help them learn better. However, a few pre-service teachers think that making comparison activities on Edmodo is a waste of time.

For homework and messaging on Edmodo, they liked it most that Edmodo makes it easy to communicate. Also getting notifications for the assignments was one of the good parts of Edmodo although notifications did not come regularly. Some preservice teachers reported that sending assignments over Edmodo was difficult. Also, pre-service teachers recommended that assignment reports must be seen by everyone in class. Reaching class documents and communicating others without time and space limit was reported one of the best sides of Edmodo.

Results are consistent with the literature for the use of Edmodo (Hamutoğlu \& Kıyıc1, 2017; Kazez \& Bahçeci, 2016; Kuzgun \& Özdinç, 2017; Dere, Yücel \& Yalçinalp, 2016). As a result, we can conclude that there is a positive effect of using Edmodo platform in mathematics curriculum class. The use of such environments in other classes might be expanded. 